CLINICAL STUDY

\title{
Follow-up of pituitary tumor volume in patients with acromegaly treated with pegvisomant in clinical trials
}

\author{
Camilo Jimenez, Pia Burman ${ }^{1}$, Roger $\mathrm{Abs}^{2}$, David R Clemmons ${ }^{3}$, William M Drake ${ }^{4}$, Kent R Hutson ${ }^{5}$, \\ Michael Messig ${ }^{6}$, Michael O Thorner ${ }^{7}$, Peter J Trainer ${ }^{8}$ and Robert F Gagel \\ Department of Endocrine Neoplasia and Hormonal Disorders, The University of Texas M.D. Anderson Cancer Center, 1515 Holcombe Boulevard Unit 435 , \\ Houston, Texas 77030, USA, ${ }^{1}$ Department of Endocrinology, University Hospital MAS, Malmö, Sweden, ${ }^{2}$ Department of Endocrinology, University of \\ Antwerp, Antwerp, Belgium, ${ }^{3}$ Endocrinology, University of North Carolina School of Medicine, Chapel Hill, North Carolina 27599, USA, ${ }^{4}$ Endocrinology, \\ St Bartholomew's Hospital, London, UK, ${ }^{5}$ Radiology, University of Tennessee College of Medicine, Chattanooga, Tennessee, USA, ${ }^{6}$ Clinical RED Statistics, \\ Pfizer Inc., New York, New York 10017, USA, ${ }^{7}$ Medicine, University of Virginia, Charlottesville, Virginia 22908, USA and ${ }^{8}$ Endocrinology, Christie \\ Hospital, Manchester, UK
}

(Correspondence should be addressed to R F Gagel; Email: rgagel@mdanderson.org)

\begin{abstract}
Objective: We examined pituitary tumor volumes in patients treated with pegvisomant for 18 months or longer, and in whom the tumors were monitored for at least 3 years. We present details on 9 of 304 patients in clinical trials with pegvisomant who experienced tumor growth within the first year of treatment. Method: Magnetic resonance images prior to start of pegvisomant and at last follow-up were examined in 43 patients ( $14 \%$ of participating patients). Twenty-nine had received prior radiation therapy ( $18 \%$ of irradiated patients) and all but five received somatostatin analogs between periods of pegvisomant treatment.

Results: At follow-up, the median tumor volume was $0.6 \mathrm{cc}$ (range $0.0-19.7 \mathrm{cc}$ ), in comparison with $1.6 \mathrm{cc}$ $(0.0-19.7 \mathrm{cc})$ at baseline $(P<0.001)$. Twenty-five patients, of which 23 received radiation therapy, had tumor volume reduction. Seventeen patients had no significant change. One patient, who had not received radiation therapy, had an increase in tumor volume from 1.61 to $1.93 \mathrm{cc}$. Of the nine patients with tumor growth, six had progressive growth before initiating pegvisomant. Two patients with stable tumors while on octreotide experienced enlargement after octreotide discontinuation but remained stable on long-term pegvisomant therapy.

Conclusion: The present data indicate that pegvisomant does not promote tumor growth and suggest that the nine observed cases of tumor progression, which occurred within 8 months after commencing pegvisomant, are likely rebound expansions after discontinuation of somatostatin analogs and/or the natural history of aggressively growing pituitary tumors. Continued long-term surveillance of tumor volume, particularly in non-irradiated patients, is recommended.
\end{abstract}

European Journal of Endocrinology 159 517-523

\section{Introduction}

Acromegaly is typically present for a decade prior to the diagnosis being made, and at that stage about $70 \%$ of the growth hormone $(\mathrm{GH})$-secreting tumors are macroadenomas (1). Therapy is focused on eradication of tumor mass and, if that is not possible, normalization of the metabolic and clinical abnormalities. GH overproduction increases the risk for diabetes mellitus, cardiovascular disease, pulmonary disease, and possibly cancer, collectively reducing the life expectancy of uncontrolled patients (2-6).

Surgery is the most effective, potentially curative, therapy. However, most patients with acromegaly present with infiltrative macro-adenomas or with unresectable adenomas because of difficult location. Surgical remission rates of $50 \%$ for macro-adenomas and $70-80 \%$ for micro-adenomas have been reported (7-9). Radiation therapy may ultimately normalize serum insulin-like growth factor-I (IGF-I); however, it may take many years to observe adequate control of the excessive GH production (10-12). Unfortunately, radiation therapy is associated with an increased risk for pituitary insufficiency, possibly cerebrovascular accidents, and rarely $\mathrm{CN}$ tumors (13-16). Medical therapy (dopamine agonists, somatostatin analogs, and GH receptor antagonist) is often necessary for optimal treatment as a significant proportion of patients remain with elevated IGF-I after surgery and/or radiation therapy (17). Dopamine agonists interact with the pituitary D2 receptors, triggering a not well-understood biochemical response that decreases the secretion of GH in some patients (10-34\%) (18). Somatostatin analogs interact with somatostatin receptors, principally subtypes 2 and 5, inhibiting $\mathrm{GH}$ secretion and thereby normalizing IGF-I in about $50-70 \%$ of patients (19-22).

Pegvisomant is a $\mathrm{GH}$ receptor antagonist that blocks the action of GH by competitively inhibiting GH binding 
to the preformed $\mathrm{GH}$ receptor dimer. At doses up to $40 \mathrm{mg} /$ day, it is capable of normalizing circulating IGF-I in $97 \%$ of patients (23). Unlike other modes of therapy it does not attempt to lower serum GH levels, and its efficacy is unrelated to any action on the pituitary tumor. Circulating GH levels approximately double on initiation of pegvisomant therapy, which is believed to be a consequence of a feedback response to the fall in plasma IGF-I. Since clinical trials began in mid-90s, there has been concern that pegvisomant might be associated with tumor growth, because the natural history of tumors is to expand, or alternatively, and more sinisterly, that a feedback increase in GH secretion would result in accelerated tumor growth. To date, there is limited published experience of tumor volume changes in pegvisomant-treated patients. In total, tumor growth has been observed in 9 of 304 patients taking part in clinical trials, i.e. an incidence of $\sim 3 \%$ (24). In these instances, tumor growth was evident within the first 6-12 months of treatment, e.g. van der Lely et al. $(23,25)$ observed tumor growth within 12 months of treatment in 2 of 160 patients treated for an average of 425 days, Colao et al. (26) noted tumor growth in 2 patients after 6 months of treatment with pegvisomant, and Frohman reported a woman with tumor growth 6 months after start of pegvisomant therapy (27). After conversion from octreotide longacting release (LAR) to pegvisomant, one patient had significant tumor growth $(>20 \%)$ while on pegvisomant therapy. The expansion was observed 6 months after the last dose of octreotide LAR had been given (28). During further treatment with pegvisomant for an additional 21 months tumor volume remained stable. Three patients have not been reported previously. In addition, we provide previously unpublished details of the nine cases who experienced tumor growth within 12 months after starting treatment with pegvisomant. The incidence of tumor growth on pegvisomant when used in clinical practice is similar to that found in clinical trials, as illustrated by a recent report by Schreiber et al. (29). When assessed by a central evaluator 7 of 229 patients had confirmed tumor growth. As discussed (24), an increase in tumor volume might be explained by rebound expansion after discontinuation of somatostatin analog therapy or by continuation of a tumor growth that started prior to initiation of pegvisomant therapy.

Previous data have been based on treatment with pegvisomant for up to 18 months; experience with longer term therapy has not been reported. Here, we have reviewed a series of pituitary magnetic resonance images (MRIs) from patients treated with pegvisomant for 18 months and longer within monitored clinical trials in which tumor volumes were evaluated by the same examiner. We also provide previously unpublished data on the nine subjects who experienced tumor growth during short-term treatment with pegvisomant.

\section{Study design and subjects}

A total of 304 patients have been treated with pegvisomant in sponsored clinical trials. A prerequisite for participation in the trials was that if treatment with radiotherapy had been given it had to have taken place more than 12 months before enrolment. The duration of follow-up in this cohort is as follows, $<6$ months $n=51$, 6 to $<12$ months $n=88,12$ to $<24$ months $n=83,24$ to $<36$ months $n=31$, and $\geq 36$ months $n=51$. Treatment with pegvisomant for up to 18 months is here considered as treatment of a short-term duration. In this group, nine subjects experienced tumor growth (Table 2). We have compiled detailed and previously unpublished data on these nine cases. The information on treatment for tumor growth and exposure time to other medications for acromegaly was provided by their respective treating physician. To be eligible for the long-term follow-up part, the present subjects had to have received treatment with pegvisomant for $\geq 18$ months and been monitored with MRIs for at least 36 months. Forty-three patients (14\% subjects participating patients in the sponsored clinical trials) met the inclusion criteria. Compared with the complete study cohort of 304 subjects, these 43 patients had similar age and sex distribution, 46 (20-72) years, 49\% men versus 46 (20-84) years, 57\% men, similar IGF-I levels prior to pegvisomant, 671 (399-2131) $\mu \mathrm{g} / \mathrm{l}$ versus $668(101-2173) \mu \mathrm{g} / \mathrm{l}$, and a comparable treatment regimen prior to enrolment, surgery in $88 \%$ vs $82 \%$, prior radiation therapy in 62 vs $52 \%$. These subjects had been enroled in a Phase II and subsequently in a Phase III, multicenter, randomized, double-blind, fixed-dose, placebo-controlled trial (Table 1). The subjects were changed to long-acting octreotide after conclusion of the study and then participated in a Phase IV trial designed to evaluate pharmacologic effects of conversion of long-acting octreotide to pegvisomant (28-week trial), after which the majority of subjects continued in a compassionate use program until pegvisomant was commercially available in their respective countries. In this program, $73 \%$ of the patients achieved an IGF-I level below the upper limit of normal (ULN) at the end of the core protocol (week 32), while $89.7 \%$ experienced a reduction to below the ULN at any time, i.e., during either the core or extension phase. Post-hoc summaries of dose titration and the doses at which an IGF-I below ULN was achieved revealed that in patients with IGF-I levels above the ULN an average of $57 \%$ did not have their dose increased as specified in the protocol. The average duration of treatment with pegvisomant was $29 \pm 7$ months (range 18-45). All but five patients had received treatment with somatostatin analogs between taking part in clinical trials with pegvisomant. The average accumulated exposure in the patients treated with somatostatin analogs was $17 \pm 8$ months (range 2-30). The average uninterrupted length of 
Table 1 Participation in various trials of the 43 patients followed-up long term.

\begin{tabular}{|c|c|c|c|c|c|}
\hline \multicolumn{5}{|c|}{ Trial protocols } & \multirow{2}{*}{$\frac{\boldsymbol{N}}{1}$} \\
\hline $3611 \rightarrow$ & & $3613 A \rightarrow$ & MET007 $\rightarrow$ & SOMAV1011 $\rightarrow$ & \\
\hline $3611 \rightarrow$ & $3613 \rightarrow$ & $3613 A \rightarrow$ & & SOMAV $1011 \rightarrow$ & 4 \\
\hline $3611 \rightarrow$ & $3613 \rightarrow$ & $3613 A \rightarrow$ & MET007 & & 3 \\
\hline \multirow[t]{2}{*}{$3611 \rightarrow$} & $3613 \rightarrow$ & $3613 \mathrm{~A} \rightarrow$ & MET007 $\rightarrow$ & SOMAV1011 $\rightarrow$ & 8 \\
\hline & $3613 \rightarrow$ & $3613 A \rightarrow$ & & SOMAV $1011 \rightarrow$ & 1 \\
\hline $3614 \rightarrow$ & & & MET007 $\rightarrow$ & SOMAV $1011 \rightarrow$ & 1 \\
\hline $3614 \rightarrow$ & $3615 \rightarrow$ & & & SOMAV $1011 \rightarrow$ & 1 \\
\hline $3614 \rightarrow$ & $3615 \rightarrow$ & & MET007 $\rightarrow$ & & 1 \\
\hline $3614 \rightarrow$ & $3615 \rightarrow$ & & MET007 $\rightarrow$ & SOMAV1011 $\rightarrow$ & 23 \\
\hline & & & & & Total $=43$ \\
\hline
\end{tabular}

SEN 3611; Phase II b, weekly dosing ( 30 and $80 \mathrm{mg}$ pegvisomant) for 6 weeks. SEN 3613; open label, daily dosing (10, 15, and $20 \mathrm{mg}$ pegvisomant) for up to 34 weeks. SEN 3613 A; open-label extension study for up to 162 weeks. SEN 3614; Phase III, placebo controlled (10, 15 and $20 \mathrm{mg}$ pegvisomant) for 12 weeks. SEN 3615; open-label extension study for up to 52 weeks. 467 MET 9119-007: open 32-week study with 10-25 mg pegvisomant. in patients treated with octreotide LAR for $\geq 3$ months. SOMV 9119-010/011; a compassionate use program in patients who had failed conventional therapy.

treatment with pegvisomant in all patients was $20 \pm 6$ months. Treatment with pegvisomant was continued through the final MRI evaluation.

The primary endpoint was a change in pituitary tumor volume from baseline MRI (MRI at the time of first enrolment into a clinical trial with pegvisomant) to the last MRI. The mean duration of follow-up, i.e. time from baseline MRI to last MRI during treatment with pegvisomant, was $58+7$ months (range 46-73).

\section{Assessment of pituitary MRIs}

MRIs of the pituitary gland were obtained at defined time points, including a study prior to pegvisomant and at study conclusion. Coronal and sagittal T1-weighted images were obtained before and after the administration of gadolinium contrast. MRI films were scanned with a high-resolution L75 film scanner (Lumisys Inc., Sunnyvale, CA, USA) or submitted on DICOM CD-ROM. The pituitary adenomas were measured by one neuroradiologist $(\mathrm{K} \mathrm{H})$ who used hand tracings in conjunction with NIH image analysis software (Scion Corp., Frederick, MD, USA) for analysis. Total tumor volume was estimated by multiplying each slice thickness by the area inside the curve of the hand-traced image, then summing the volumes of the slices (30). Maximum diameter in each dimension was measured.

Inherent in accurate measurement and assessment of tumor volumes is an understanding of the limitations of the technique. In tumors with a volume of 1 cc or larger, a change in tumor volume $\geq 20 \%$ was considered significant (31). In tumors smaller than $1 \mathrm{cc}$, the average MRI image thickness of $3 \mathrm{~mm}$ limits the ability to detect small percentage changes in a tumor. At this slice thickness, a minimum diameter change of $3 \mathrm{~mm}$ is necessary for it to be considered significant (32). Smaller changes in the pituitary tumor volumes may be attributable to volume average artifacts or changes in slice position. To avoid the possibility of overestimating any change in tumor size for tumors $<1 \mathrm{cc}$ in size, we have applied the more stringent definition, i.e. at least $3 \mathrm{~mm}$ change in one diameter.
We recognize that this necessitates dual criteria for significant change in small $(<1 \mathrm{cc})$ and large $(\geq 1 \mathrm{cc})$ tumor volumes, necessitated by the measurement characteristics of the technique. It should also be pointed out that these criteria of $<$ or $\geq 1 \mathrm{cc}$ do not refer to the conventional definition of micro- and macro-adenoma and are used only to define the interface at which the slice thickness becomes a limiting factor in assessing significant change in the size of the tumor.

\section{Statistical analysis}

The descriptive summaries included means, medians, S.D.s, and ranges (minimum/maximum) for continuous variables and counts and number and percentages for categorical variables. The mean change from baseline in tumor volume was tested for significance using a paired $t$-test with a two-sided $P$ value of less than 0.05 considered significant.

\section{Results}

\section{Characteristics of the nine patients with tumor growth while on short-term treatment with pegvisomant in clinical trials}

As previously reported among the 304 patients treated in clinical trials 9 patients experienced tumor growth, all within the first year of treatment (24). Further details are given here. Eight patients had large pituitary tumors at diagnosis and had been treated with surgery; patient number 7 had an intrasellar micro-adenoma with evidence of lateral extension into the cavernous sinus and consequently, this patient was not considered a candidate for surgery (Table 2). None of the patients had received radiotherapy prior to pegvisomant. In seven patients, treatment with pegvisomant was preceded by treatment with long-acting octreotide. Patient number 1 was treated with short-acting octreotide prior to pegvisomant but developed a 
Table 2 Characteristics of the nine patients with tumor growth while on pegvisomant.

\begin{tabular}{|c|c|c|c|c|c|c|c|c|}
\hline Patient/Ref. & Sex/age & $\begin{array}{l}\text { Tumor } \\
\text { growth prior } \\
\text { to pegv. }\end{array}$ & $\begin{array}{l}\text { Treated with } \\
\text { octreotide } \\
\text { LAR prior to } \\
\text { pegv. }\end{array}$ & $\begin{array}{c}\text { Tumor at } \\
\text { start of } \\
\text { pegv. }\end{array}$ & $\begin{array}{l}\text { Time to } \\
\text { increase in } \\
\text { tumor size } \\
\text { after start of } \\
\text { pegv. } \\
\text { (months) }\end{array}$ & $\begin{array}{l}\text { Tumor on } \\
\text { continued } \\
\text { treatment } \\
\text { with pegv. }\end{array}$ & $\begin{array}{l}\text { Treatment for } \\
\text { tumor } \\
\text { progression }\end{array}$ & Ongoing therapy \\
\hline 1. (23) & F 26 & $Y_{e s}^{a}$ & No & Macro & 7 & NA & Radiotherapy & SSA \\
\hline 2. $(23,25)$ & M 32 & $\begin{array}{l}\text { No data } \\
\quad \text { available }\end{array}$ & Yes $^{b}$ & Macro & 6 & Growth & $\begin{array}{l}\text { Surgery, } \\
\text { radiotherapy }\end{array}$ & Pegv. \\
\hline 3. & F 33 & Yes $^{\mathrm{c}}$ & Yes & Macro & 6 & NA & Surgery & Unknown \\
\hline 4. (27) & F 33 & Yes $^{d}$ & Yes & Macro & 6 & NA & SSA, surgery & SSA \\
\hline 5. & $\mathrm{~F} 61$ & $Y_{e s}^{c}$ & Yes & Macro & 6 & Growth & $\begin{array}{l}\mathrm{SSA}^{\mathrm{e}} \text {, surgery, } \\
\text { radiotherapy }\end{array}$ & Pegv. + SSA \\
\hline 6. (28) & M 53 & No & Yes & Macro & 6 & Stable & None & Pegv. \\
\hline 7. & M 64 & No & Yes & Micro & 8 & Stable & None & Pegv. \\
\hline 8. (26) & M 43 & Yes $^{a}$ & Yes & Macro & 6 & Growth & Addition of SSA & Pegv.+SSA \\
\hline 9. (26) & M 32 & $Y_{e s}^{a}$ & Yes & Macro & 6 & Growth & Addition of SSA & Pegv. +SSA \\
\hline
\end{tabular}

NA, not applicable since surgery/radiotherapy was performed when tumor growth was observed; SSA, somatostatin analogs.

${ }^{a}$ While on no medication.

${ }^{b}$ Octretide sc.

'While on long-acting SSA.

${ }^{d}$ During pregnancy while on no treatment.

${ }^{\mathrm{e}}$ The tumor continued to grow resulting in visual field defects while on pasireotide for 6.5 months.

pronounced skin rash within a week necessitating discontinuance of octreotide. Patient number 2 received short-acting octreotide 2 months prior to initiation of pegvisomant. In six cases, tumor growth prior to the start of pegvisomant was documented, either during a period of no medical treatment (pts $1,4,8,9$ ) or while on somatostatin analogs (pts 3, 5). Six to eight months into the pegvisomant trial an increase in tumor volume was noted in the nine patients. The maximal median increase in tumor volume in these nine patients was $68 \%$ (range 26-182\%). In four cases (pts 1, 3, 4, 5), treatment for tumor progression, i.e. surgery and/or radiotherapy, was performed shortly after the first MRI showed progression; in the other five cases, the investigators elected to continue treatment with pegvisomant within the clinical trial. In one previously unreported woman (pt 5), who had the most pronounced tumor expansion while on pegvisomant, the disease activity had initially been controlled on dopamine agonists which was followed by a more aggressive course characterized by elevated GH/IGF-I levels and tumor growth also after addition of somatostatin analogs. After discontinuation of pegvisomant, the tumor continued to grow while on treatment with pasireotide. In patient 6 , the tumor measured 1.33 $\mathrm{cc}$ while on treatment with octreotide. Eight months after discontinuation of octreotide LAR and while on treatment with pegvisomant the tumor volume increased to $2.24 \mathrm{cc}(68 \%)$. In patient 7 , the tumor size was $0.34 \mathrm{cc}$ upon discontinuation of octreotide LAR. Eight months later, the tumor volume doubled to 0.7 cc. In both cases (pts. 6, 7), tumor volumes have remained stable upon continued treatment with pegvisomant for 30 and 36 months respectively, suggesting an initial rebound expansion after discontinuation of octreotide LAR.

\section{Long-term treatment ( $>18$ months) and follow-up (>46 months) in clinical trials - patient characteristics}

Forty-three patients (21 men, 22 women) with a mean age \pm s.D. of $46 \pm 12$ years at the initiation of pegvisomant were included. Twenty-eight subjects received a combination of surgery, radiation, and medical therapy prior to pegvisomant therapy (65.1\%). Ten had surgery and medical therapy $(23.3 \%)$, four had only medical therapy $(9.3 \%)$, and one had radiation and medical therapy. Regarding the medical therapy, all but one patient had received treatment with a short-acting somatostatin analog before enroling into the first trial with pegvisomant and 26 subjects $(60.5 \%)$ had been treated with a dopamine agonist.

\section{Dose of pegvisomant, IGF-I, and GH concentrations}

The mean \pm s.D. final dose of pegvisomant was $18.7 \pm$ $8.0 \mathrm{mg} /$ day $($ median $=20$, range 10-40). At baseline, 42 patients $(98 \%)$ had uncontrolled acromegaly with a median IGF-I value of 671 (range 369-2131 ng/ml) and a median GH value of 5.1 (range $0.3-138 \mathrm{ng} / \mathrm{ml}$ ). At the time of the last pituitary MRI, the patients had a marked reduction of the IGF-I values to 257 (range 111-952 ng/ml) including 34 patients with normal concentrations of IGF-I according to age and gender (see Study design and subjects). As expected, patients treated with pegvisomant exhibited increased 
GH values (median 9.0, range 0-191 ng/ml) when compared with baseline.

\section{Tumor volume by MRI}

Baseline pituitary MRIs identified 29 patients with residual tumor volumes of $\geq 1 \mathrm{cc}$ and 14 patients with residual tumor volumes of $<1 \mathrm{cc}$ in size. The median baseline tumor volume for the whole group was 1.6 (range $0.0-19.7 \mathrm{cc}$ ). After $58 \pm 7$ months of follow-up, the tumor volume was reduced to 0.6 (range $0.0-19.7 \mathrm{cc})$, a median change of $-53.9 \%(P<0.001$; Fig. 1). When using the $20 \%$ criterion as a definition of change in tumor volume, 31 patients had a decrease in tumor volume. When applying the more stringent definition of a significant change in tumor size (see Assessment of pituitary MRIs), this figure was reduced to $24(56 \%)$ subjects. The 22 of these subjects had received prior radiation therapy. The baseline median tumor volume for the 29 patients with prior radiotherapy was 2.7 (range 0.0-19.7 cc) and 0.6 (range 0.0-19.7 cc) at final MRI (a median change of $-56.7 \%$, $P<0.0001)$. The baseline median tumor volume for the subgroup of 14 patients with no prior radiation was 0.6 (range $0.1-4.7 \mathrm{cc}$ ) and 0.6 (range $0.0-4.5 \mathrm{cc}$ ) at the final MRI, a median change of $-13.6 \%(P=N S)$. One patient, who had not received radiation therapy, had an increase in tumor volume from 1.61 to $1.93 \mathrm{cc}$.

\section{Other patients treated on clinical trials or compassionate use protocols}

Two hundred and fifty-two patients received pegvisomant for varying periods of time prior to drug approval. The lack of long-term information (MRI or hormonal data) on these makes it impossible to assess their longterm response to therapy. However, the manufacturer has received no reports of tumor growth in this cohort.

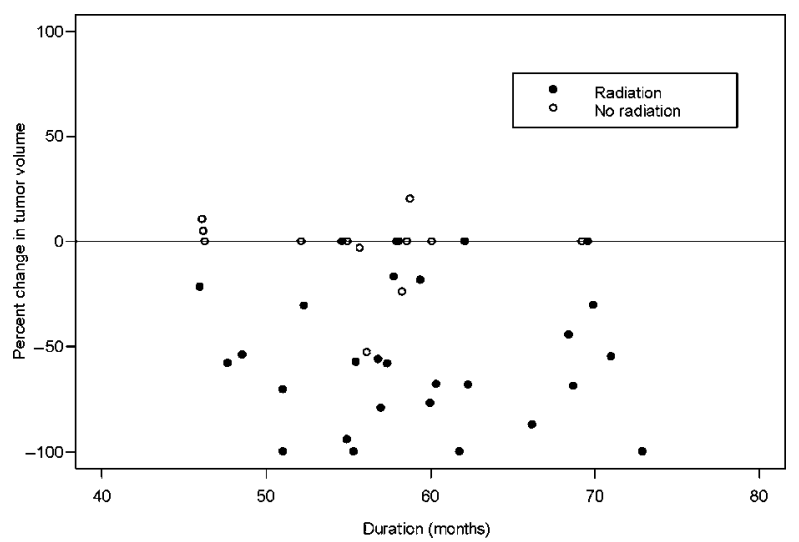

Figure 1 Changes in tumor volume in all subjects $(n=43)$. Filled circles, patients with prior radiotherapy; open circles, patients with no prior radiotherapy.

\section{Discussion}

The natural history of a non-functioning pituitary tumor is defined by growth as illustrated by the relative high frequency of regrowth post-surgery $(33,34)$. In a study where serial imaging of pituitary tumor remnants post-surgery was performed, the calculated tumor doubling time was considerably lower in younger patients (35). In somatotropinomas, the natural history of tumor behavior is less well-known since prolonged elevation of plasma $\mathrm{GH}$ necessitates intervention. However, at presentation, younger patients tend to have higher $\mathrm{GH}$ levels and larger tumors (36). Besides patient age, mutations in a series of genes affecting intracellular signaling or growth factor pathways of the pituitary cells have been linked to the clinical behavior as well as the risk of recurrence on a group level. For the individual patient, there is, however, no reliable predictor (37). Although somatostatin analogs reduce tumor size in a significant proportion of subjects, tumor growth while on treatment occurs in about $2 \%(38,39)$, again illustrating tumor heterogeneity with a more aggressive behavior in certain somatropinomas.

Pegvisomant does not act on the pituitary to reduce circulating $\mathrm{GH}$ concentrations but rather blocks $\mathrm{GH}$ binding to target tissue $\mathrm{GH}$ receptors. When clinical trials began in the mid-90s, it was thought that in the absence of pituitary-oriented therapy there was the possibility that tumors would increase in size during pegvisomant treatment. Initiation of pegvisomant results in a fall in IGF-I levels and through feedback mechanisms an increase in circulating GH levels $(26$, 40). What was less certain when pegvisomant was first administered to patients was whether the mechanisms responsible for the increased GH secretion would also stimulate tumor growth. The recognition of this possibility led to a study design that included frequent, centralized, and detailed measurement of tumor volume. The patients entering the trials had elevated IGF-I levels and as is inevitable for a new treatment modality most had failed to respond to conventional treatment with normalization of IGF-I, with $85 \%$ having had surgery, and $75 \%$ somatostatin analogs. In the cohort encompassing 304 patients in sponsored clinical trials with a cumulative experience of 452 patient years, tumor growth was seen in 9 patients. In these cases, tumor growth was evident within the first year of treatment; none of the patients had received radiation therapy. Importantly, tumor growth had occurred in six of these cases prior to the start of pegvisomant, when these patients were on no medical treatment or while on treatment with somatostatin analogs. Six of the nine patients were under the age of 45 years, compatible with a more aggressive growth pattern observed in younger patients with somatropinomas (36), and all were unirradiated. It is possible that some of the growth could be explained by a rebound from suppression by somatostatin analogs as observed 
in patients numbers 6 and 7 (Table 1) after conversion from octreotide to pegvisomant. Six of the patients remain on pegvisomant, in three cases in combination with a somatostatin analog, without evidence of further tumor growth.

While these findings are reassuring they do not address the important question of whether long-term therapy with pegvisomant is associated with pituitary tumor growth. To address this question, we identified all patients from the Phases II-IV trials who had been treated with pegvisomant for at least 18 months (mean of 29 months) and also had pituitary imaging at regular intervals. As detailed in Study design and subjects, these 43 patients were comparable with the overall study cohort of 304 subjects with respect to age, gender, IGF-I levels prior to start of pegvisomant, and previous surgery (88 vs $82 \%$ ). Prior radiation therapy was slightly more common, (62 vs $52 \%$ ), probably reflecting that subjects enroled in the early pegvisomant protocols had been patients difficult to manage. The results showed no significant change in pituitary volume in unirradiated patients treated with pegvisomant. As these patients had consistent elevations of their plasma $\mathrm{GH}$ concentrations during therapy, we interpret these findings to suggest a disconnect between the hormonal feedback loop and growth. Thus, the concern that pegvisomant treatment might be a stimulus to pituitary growth is unsubstantiated by this analysis.

The data in this manuscript also provide the most compelling dataset available demonstrating that external beam radiation followed by pegvisomant is associated with a reduction in tumor size. Earlier reports utilized a skilled radiologist's interpretation to provide a qualitative estimate of growth, stability, and shrinkage. In one of the best reports describing the effect of radiation in patients with non-functional pituitary tumors, 33\% of irradiated patients had tumor growth (41), in a second series focused on GH-producing pituitary tumors, reduction was found in $14.9 \%$, stable tumor size in $80.7 \%$, and tumor growth in $4.4 \%$ over a mean of 12 years following conventional radiotherapy (42). Our dataset, obtained at variable time points following pituitary irradiation, documents that a combination of external beam therapy and pegvisomant was associated with almost a $60 \%$ reduction in pituitary tumor volume. As there was no significant change in pituitary volume in the patients without prior radiation treated with pegvisomant, we conclude the shrinkage effect is likely related to radiation.

In conclusion, analysis of the short- and long-term experience indicates that tumor growth may be seen early in the course of treatment which probably reflects the natural history of certain tumors, while if no tumor occurs in the first 18 months, then it is unlikely to occur subsequently suggesting that pegvisomant treatment per se does not promote tumor growth. Treatment with somatostatin analogs is known to reduce tumor volume in certain patients, and therefore, discontinuation may result in rebound expansion appearing after initiation of pegvisomant. A small percentage of patients with GH-producing tumors, mostly younger, will have aggressive growth despite therapeutic intervention with somatostatin analogs or pegvisomant and close monitoring will be required. Finally, external beam therapy is associated with a reduction of pituitary size. Although we find no evidence of pituitary tumor growth, we consider it important to monitor all patients on pegvisomant using MRI scans, and that longer term data should be collected in a surveillance registry.

\section{Declaration of interest}

Michael Messig is a Pfizer employee, Pia Burman is a Pfizer consultant.

\section{Funding}

This research project has been supported by Pfizer Pharmaceuticals.

\section{Acknowledgements}

We are thankful to Drs Annamaria Colao, Aart-Jan van der Lely, and Gudmundur Johannsson for providing detailed information on their respective patients. We would also like to thank Charles Stava for his assistance with the manuscript preparation and editing.

\section{References}

1 Scacchi M \& Cavagnini F. Acromegaly. Pituitary 20069 297-303.

2 Rajasoorya C, Holdaway IM, Wrightson P, Scott DJ \& Ibbertson HK. Determinants of clinical outcome and survival in acromegaly. Clinical Endocrinology 199441 95-102.

3 Freda PU, Wardlaw SL \& Post KD. Long-term endocrinological follow-up evaluation in 115 patients who underwent transsphenoidal surgery for acromegaly. Journal of Neurosurgery $1998 \mathbf{8 9}$ 353-358.

4 Holdaway IM \& Rajasoorya C. Epidemiology of acromegaly. Pituitary 19992 29-41.

5 Melmed S. Acromegaly and cancer: not a problem? Journal of Clinical Endocrinology and Metabolism 200186 2929-2934.

6 Prabhu SS, Aldape KD, Gagel RF, Benjamin RS, Trent JC \& McCutcheon IE. Sarcomatous change after sellar irradiation in a growth hormone-secreting pituitary adenoma. Canadian Journal of Neurological Sciences 200330 378-383.

7 Laws ER. Surgery for acromegaly: evolution of the techniques and outcomes. Reviews in Endocrine and Metabolic Disorders 20089 67-70.

8 Nomikos P, Buchfelder M \& Fahlbusch R. The outcome of surgery in 668 patients with acromegaly using current criteria of biochemical 'cure'. European Journal of Endocrinology 2005152 379-387.

9 Ludecke DK \& Abe T. Transsphenoidal microsurgery for newly diagnosed acromegaly: a personal view after more than 1,000 operations. Neuroendocrinology 200683 230-239.

10 Eastman RC, Gorden P, Glatstein E \& Roth J. Radiation therapy of acromegaly. Endocrinology and Metabolism Clinics of North America 199221 693-712.

11 Biermasz NR, Dulken HV \& Roelfsema F. Postoperative radiotherapy in acromegaly is effective in reducing $\mathrm{GH}$ concentration to safe levels. Clinical Endocrinology 200053 321-327.

12 Melmed S. Medical progress: acromegaly. New England Journal of Medicine $20063552558-2573$. 
13 Snyder PJ, Fowble BF, Schatz NJ, Savino PJ \& Gennarelli TA. Hypopituitarism following radiation therapy of pituitary adenomas. American Journal of Medicine 198681 457-462.

14 Littley MD, Shalet SM, Beardwell CG, Robinson EL \& Sutton ML. Radiation-induced hypopituitarism is dose-dependent. Clinical Endocrinology 198931 363-373.

15 Millar JL, Spry NA, Lamb DS \& Delahunt J. Blindness in patients after external beam irradiation for pituitary adenomas: two cases occurring after small daily fractional doses. Clinical Oncology 1991 3 291-294.

16 Meyers CA, Geara F, Wong PF \& Morrison WH. Neurocognitive effects of therapeutic irradiation for base of skull tumors. International Journal of Radiation Oncology, Biology, Physics 2000 46 51-55.

17 Racine MS \& Barkan AL. Medical management of growth hormone-secreting pituitary adenomas. Pituitary 20025 67-76.

18 Melmed S, Vance ML, Barkan AL, Bengtsson BA, Kleinberg D, Klibanski A \& Trainer PJ. Current status and future opportunities for controlling acromegaly. Pituitary 20025 185-196.

19 Freda PU. Somatostatin analogs in acromegaly. Journal of Clinical Endocrinology and Metabolism 200287 3013-3018.

20 Freda PU. How effective are current therapies for acromegaly? Growth Hormone and IGF Research 200313 (Suppl A) S144-S151.

21 Cozzi R, Montini M, Attanasio R, Albizzi M, Lasio G, Lodrini S, Doneda P, Cortesi L \& Pagani G. Primary treatment of acromegaly with octreotide LAR: a long-term (up to nine years) prospective study of its efficacy in the control of disease activity and tumor shrinkage. Journal of Clinical Endocrinology and Metabolism 2006 91 1397-1403.

22 Ben-Shlomo A \& Melmed S. Somatostatin agonists for treatment of acromegaly. Molecular and Cellular Endocrinology 2008286 192-198.

23 van der Lely AJ, Hutson RK, Trainer PJ, Besser GM, Barkan AL, Katznelson L, Klibanski A, Herman-Bonert V, Melmed S, Vance ML, Freda PU, Stewart PM, Friend KE, Clemmons DR, Johannsson G, Stavrou S, Cook DM, Phillips LS, Strasburger CJ, Hackett S, Zib KA, Davis RJ, Scarlett JA \& Thorner MO. Long-term treatment of acromegaly with pegvisomant, a growth hormone receptor antagonist. Lancet $20013 \mathbf{3 8} 1754-1759$.

24 Besser GM, Burman P \& Daly AF. Predictors and rates of treatment-resistant tumor growth in acromegaly. European Journal of Endocrinology 2005153 187-193.

25 van der Lely AJ, Muller A, Janssen JA, Davis RJ, Zib KA, Scarlett JA \& Lamberts SW. Control of tumor size and disease activity during cotreatment with octreotide and the growth hormone receptor antagonist pegvisomant in an acromegalic patient. Journal of Clinical Endocrinology and Metabolism 200186 478-481.

26 Colao A, Pivonello R, Auriemma RS, De Martino MC, Bidlingmaier M, Briganti F, Tortora F, Burman P, Kourides IA, Strasburger CJ \& Lombardi G. Efficacy of 12-month treatment with the $\mathrm{GH}$ receptor antagonist pegvisomant in patients with acromegaly resistant to long-term, high-dose somatostatin analog treatment: effect on IGF-I levels, tumor mass, hypertension and glucose tolerance. European Journal of Endocrinology $2006 \mathbf{1 5 4}$ $467-477$.

27 Frohman LA \& Bonert V. Pituitary tumor enlargement in two patients with acromegaly during pegvisomant therapy. Pituitary 200710 283-289.

28 Barkan AL, Burman P, Clemmons DR, Drake WM, Gagel RF Harris PE, Trainer PJ, van der Lely AJ \& Vance ML. Glucose homeostasis and safety in patients with acromegaly converted from long-acting octreotide to pegvisomant. Journal of Clinical Endocrinology and Metabolism 200590 5684-5691.

29 Schreiber I, Buchfelder M, Droste M, Forssmann K, Mann K, Saller B \& Strasburger CJ. Treatment of acromegaly with the GH receptor antagonist pegvisomant in clinical practice: safety and efficacy evaluation from the German Pegvisomant Observational Study. European Journal of Endocrinology 2007156 75-82.
30 Lundin P \& Pedersen F. Volume of pituitary macroadenomas: assessment by MRI. Journal of Computer Assisted Tomography 1992 16 519-528.

31 Bevan JS, Atkin SL, Atkinson AB, Bouloux PM, Hanna F, Harris PE, James RA, McConnell M, Roberts GA, Scanlon MF, Stewart PM, Teasdale E, Turner HE, Wass JA \& Wardlaw JM. Primary medical therapy for acromegaly: an open, prospective, multicenter study of the effects of subcutaneous and intramuscular slow-release octreotide on growth hormone, insulin-like growth factor-I, and tumor size. Journal of Clinical Endocrinology and Metabolism 200287 4554-4563.

32 Therasse P, Arbuck SG, Eisenhauer EA, Wanders J, Kaplan RS, Rubinstein L, Verweij J, Van Glabbeke M, van Oosterom AT, Christian MC \& Gwyther SG. New guidelines to evaluate the response to treatment in solid tumors. European Organization for Research and Treatment of Cancer, National Cancer Institute of the United States, National Cancer Institute of Canada. Journal of the National Cancer Institute 200092 205-216.

33 Colao A, Cerbone G, Cappabianca P, Ferone D, Alfieri A, Di Salle F, Faggiano A, Merola B, de Divitiis E \& Lombardi G. Effect of surgery and radiotherapy on visual and endocrine function in nonfunctioning pituitary adenomas. Journal of Endocrinological Investigation 199821 284-290.

34 Greenman Y, Ouaknine G, Veshchev I, Reider G II, Segev Y \& Stern N. Postoperative surveillance of clinically nonfunctioning pituitary macroadenomas: markers of tumour quiescence and regrowth. Clinical Endocrinology 200358 763-769.

35 Tanaka Y, Hongo K, Tada T, Sakai K, Kakizawa Y \& Kobayashi S. Growth pattern and rate in residual nonfunctioning pituitary adenomas: correlations among tumor volume doubling time, patient age, and MIB-1 index. Journal of Neurosurgery 200398 359-365.

36 Klijn JG, Lamberts SW, de Jong FH, van Dongen KJ \& Birkenhager JC. Interrelationships between tumour size, age, plasma growth hormone and incidence of extrasellar extension in acromegalic patients. Acta Endocrinologica 198095 289-297.

37 Donangelo I \& Melmed S. Implication of pituitary tropic status on tumor development. Frontiers of Hormone Research 200635 1-8.

38 Bevan JS. Clinical review: the antitumoral effects of somatostatin analog therapy in acromegaly. Journal of Clinical Endocrinology and Metabolism 200590 1856-1863.

39 Freda PU, Katznelson L, van der Lely AJ, Reyes CM, Zhao S \& Rabinowitz D. Long-acting somatostatin analog therapy of acromegaly: a meta-analysis. Journal of Clinical Endocrinology and Metabolism 200590 4465-4473.

40 Trainer PJ, Drake WM, Katznelson L, Freda PU, Herman-Bonert V, van der Lely AJ, Dimaraki EV, Stewart PM, Friend KE, Vance ML, Besser GM, Scarlett JA, Thorner MO, Parkinson C, Klibanski A, Powell JS, Barkan AL, Sheppard MC, Malsonado M, Rose DR, Clemmons DR, Johannsson G, Bengtsson BA, Stavrou S, Kleinberg DL, Cook DM, Phillips LS, Bidlingmaier M, Strasburger CJ, Hackett S, Zib K, Bennett WF \& Davis RJ. Treatment of acromegaly with the growth hormone-receptor antagonist pegvisomant. New England Journal of Medicine 2000342 1171-1177.

41 Gittoes NJ, Bates AS, Tse W, Bullivant B, Sheppard MC, Clayton RN \& Stewart PM. Radiotherapy for non-function pituitary tumours. Clinical Endocrinology 199848 331-337.

42 Minniti G, Jaffrain-Rea ML, Osti M, Esposito V, Santoro A, Solda F, Gargiulo P, Tamburrano G \& Enrici RM. The long-term efficacy of conventional radiotherapy in patients with $\mathrm{GH}$-secreting pituitary adenomas. Clinical Endocrinology 200562 210-216.

Received 30 June 2008

Accepted 7 July 2008 